\title{
Doğuştan çarpık ayakta sınıflamalar
}

\section{Classifications of congenital clubfoot}

\author{
İsmail Safa Satoğlu, Haluk Berk \\ Dokuz Eylül Üniversitesi Tıp Fakültesi, İzmir
}

\begin{abstract}
Doğuştan çarpık ayak hastalığı, etiyolojik nedenlerine ve hastalığın şiddetine göre sınıflamalara ayrılabilir. Bu yazı içerisinde, etiyolojik nedenlere ek olarak özellikle Dimeglio ve Pirani sınıflamalarına ayrıntılı olarak değinilmiş, sınıflamaların alt başlıkları ve kurguları açıklanmaya çalışılmış, bazı araştırmacıların sınıflamaları güvenilirlik açısından değerlendirdikleri çalışmalardan da örnekler verilmiştir. Özetle, doğuştan çarpık ayak sınıflamaları, olguların şiddetinin belirlenmesinde ve çalışmaların birbirleriyle karşılaştırılabilmesinde büyük katkı sağlamış olmakla birlikte, tüm araştırıcıların hemfikir olduğu, prognoz konusunda ön fikir veren, tedaviyi tüm ayrıntıları ile yönlendirebilen mükemmel bir sınıflama hala geliştirilebilmiş değildir.
\end{abstract}

Anahtar sözcülkler: çarpık ayak; doğumsal kusurlar; sınıflamalar; Pirani; Dimeglio
Congenital clubfoot can be classified according to the etiology or severity of the disease. Besides the etiological causes, this review especially focuses on Dimeglio and Pirani classifications; the components and fictions behind the classifications are discussed in detail. Studies evaluating the reliability of the classifications are also cited. In summary, although the classifications of congenital clubfoot helped a lot especially in determining the severity of, and also in comparing the case series, no classification is perfect yet in describing the determinants of prognosis and guiding the treatment exclusively.

Key words: clubfoot; congenital defects; classifications; Pirani; Dimeglio

Etiyolojik nedenlerin de etkisi ile, PEV'in şiddeti olgudan olguya değişmektedir. Bu durum olgu serilerindeki başarı ve komplikasyon oranlarını belirgin bir şekilde değiştirmekte ve çalışmaların birbirleriyle karşılaştırılmasında zorluklara neden olmaktadır. PEV'de hastalıkları şiddetine göre sınıflayarak dil birliği oluşturmak amacıyla, araştırmacılar tarafından çeşitli sınıflamalar ortaya konulmuştur. Tarihsel olarak bunlardan bazıları; Ponseti ve Smoley, ${ }^{[1]}$ Harrold ve Walker, ${ }^{[2]}$ Catterall,, ${ }^{[3]}$ Carroll,, ${ }^{[4]}$ Pandey ${ }^{[5]}$ vb. sınıflamalarıdır. Ancak, bu sınıflamalar geniş bir kabul görmemiş ve yaygın bir kullanım alanı bulamamıştır. Öte yandan, 1995 yılında birbirinden bağımsız olarak, Dimeglio ve arkadaşlarının ${ }^{[6]}$ yayımladıkları bir makaledeki ve Pirani ve arkadaşlarının ${ }^{[7]}$ POSNA'da sundukları PEV sınıflamaları ilgi uyandırmış ve bunlar farklı kliniklerde PEV ile ilgili yapılan çalışmalarda sıklıkla kullanılmaya başlanmıştır.

Pirani sınıflama sisteminde, ayaktaki deformitenin statik ve düzeltilmiş durumlarının muayene bulgularının nümerik olarak puanlandırılması yapılmaktadır.

- Illetişim adresi: Dokuz Eylül Üniversitesi Tıp Fakültesi Hastanesi, Ortopedi ve Travmatoloji Anabilim Dalı Balçova, İzmir Tel: 0232 - 4123372 e-posta: safa.satoglu@deu.edu.tr

- Geliş tarihi: 25 Mayıs 2015 Kabul tarihi: 25 Mayıs 2015 
Tablo 1. Pes ekinovarus deformitesinin Pirani sınıflaması*

\begin{tabular}{|c|c|c|c|}
\hline \multirow[b]{2}{*}{ Fizik muayene bulgusu } & \multicolumn{3}{|c|}{ Puan } \\
\hline & 0 & 0,5 & 1 \\
\hline Ayak dış kenarının eğriliği & Düz & Distalde hafif eğri & Kalkaneoküboid eklemde eğrilik \\
\hline $\begin{array}{l}\text { Mediyal kıvrımın (crease) şiddeti } \\
\text { (maksimimum düzelmiş pozisyonda) }\end{array}$ & Çok sayıda ince kıvrım & Derin bir veya iki kıvrım & $\begin{array}{l}\text { Ayak konturunu değiştiren derin } \\
\text { kıvrımlar }\end{array}$ \\
\hline $\begin{array}{l}\text { Posterior kıvrımın (crease) şiddeti } \\
\text { (maksimimum düzelmiş pozisyonda) }\end{array}$ & Çok sayıda ince kıvrım & Derin bir veya iki kıvrım & $\begin{array}{l}\text { Ayak konturunu değiştiren derin } \\
\text { kıvrımlar }\end{array}$ \\
\hline $\begin{array}{l}\text { Mediyal malleol-navikula aralı̆̆ı } \\
\text { (maksimum düzelmiş pozisyonda) }\end{array}$ & Belirgin çöküklük & Aralık azalmış & Palpe edilebilir bir aralık yok \\
\hline $\begin{array}{l}\text { Talus başı lateralinin palpasyonu } \\
\text { (ayak önü maksimum } \\
\text { abduksiyonda) }\end{array}$ & $\begin{array}{l}\text { Navikula tamamen redükte } \\
\text { olur, talus başı laterali } \\
\text { hissedilemez }\end{array}$ & $\begin{array}{l}\text { Navikula kısmen redükte } \\
\text { olur, talus başı laterali az } \\
\text { hissedilebilir }\end{array}$ & $\begin{array}{l}\text { Navikula redükte olmaz, talus } \\
\text { başı laterali kolayca hissedilir }\end{array}$ \\
\hline $\begin{array}{l}\text { Topuk boşluğu } \\
\text { (ayak ve ayak bileği maksimum } \\
\text { düzeltilmiş halde) }\end{array}$ & $\begin{array}{l}\text { Kalkaneal tüberkül kolayca } \\
\text { palpe edilebilir }\end{array}$ & $\begin{array}{l}\text { Kalkaneal tüberkülü palpe } \\
\text { etmek daha zordur }\end{array}$ & $\begin{array}{l}\text { Kalkaneal tüberkül palpe } \\
\text { edilemez }\end{array}$ \\
\hline $\begin{array}{l}\text { Fibula-Aşil aralığı } \\
\text { (kalça fleksiyonda diz ekstansiyonda, } \\
\text { ayak ve ayak bileği maksimum } \\
\text { düzeltilmiş) }\end{array}$ & Belirgin çöküklük vardır & Aralık azalmıştır & Aralık palpe edilemez \\
\hline $\begin{array}{l}\text { Ekinusun şiddeti } \\
\text { (diz ekstansiyonda, ayak bileği } \\
\text { maksimum düzeltilmiş) }\end{array}$ & $\begin{array}{l}\text { Normal ayak bileği } \\
\text { dorsifleksiyonu }\end{array}$ & $\begin{array}{l}\text { Ayak bileği dorsifleksionu } \\
\text { nötralin ötesine geçemez }\end{array}$ & $\begin{array}{l}\text { Nötrale kadar dahi } \\
\text { dorsifleksiyon yapamaz }\end{array}$ \\
\hline $\begin{array}{l}\text { Adduktusun şiddeti } \\
\text { (ayak önü maksimum } \\
\text { abduksiyonda) }\end{array}$ & $\begin{array}{l}\text { Ayak önü aşırı abduksiyona } \\
\text { getirilebilir }\end{array}$ & $\begin{array}{l}\text { Ayak önü nötral abduksiyona } \\
\text { getirilebilir ama ötesine } \\
\text { geçemez }\end{array}$ & $\begin{array}{l}\text { Ayak önü nötrale kadar } \\
\text { abduksiyona getirilemez }\end{array}$ \\
\hline $\begin{array}{l}\text { Uzun fleksör kontraktürü } \\
\text { (ayak ve ayak bileği maksimum } \\
\text { koreksiyonda iken) }\end{array}$ & $\begin{array}{l}\text { MTP eklem } 90^{\circ} \text { ye kadar } \\
\text { dorsifleksiyona getirilebilir }\end{array}$ & $\begin{array}{l}\text { MTP eklem nötralin ötesine } \\
\text { dorsifleksiyona getirilebilir } \\
\text { ancak tam değildir }\end{array}$ & $\begin{array}{l}\text { MTP eklem nötrale kadar } \\
\text { dorsifleksiyona getirilemez }\end{array}$ \\
\hline
\end{tabular}

* Flynn JM, Donohoe M, Mackenzie WG. An independent assessment of two clubfoot-classification systems. J Pediatr Orthop 1998;18(3):323-7.'den modifiye edilerek türkçeleştirilmiştir.

Buna göre; deformite olmaması 0 puan alırken, orta dereceli bir deformite 0,5 puan ile değerlendirilmekte, ileri deformitelere 1 tam puan verilmektedir. Orijinalinde, ayak ortası ve ayak arkasında üçer muayene bulgusu değerlendirilip, toplam 6 puan üzerinden puanlama yapılmaktadır. Bu muayene bulguları; ayak ortası için ayak dış kenarının eğriliği, mediyal kıvrımın şiddeti ve talus başının örtülmesi iken, ayak arkası için posterior kıvrımın şiddeti, topuğun boşluğu ve ekinusun şiddetidir. Ancak, sınıflama modifiye edilerek, 10 muayene bulgusu ile 10 puan üzerinden değerlendirilmeye başlanmıştır. Değerlendirmeye alınan diğer dört bulgu; mediyal malleol-navikula aralığı, fibula-Aşil aralığı, adduktusun şiddeti ve uzun fleksör adalelerin kontraktürüdür. Buna göre en yüksek puan 10 olup, en ağır deformiteyi ifade eder. Sınıflamanın ayrıntıları aşağıdaki tabloda gösterilmektedir (Tablo 1).

Dimeglio sınıflama sisteminde ise değerlendirme, ağırlıkı olarak, deformitenin düzeltilebilirliğinin açısal dereceleri üzerinden kurgulanmıştır. Nümerik değerlendirme ise daha objektif olup, subjektif muayene bulgularına göre değil, açı ölçümlerinin objektif puanlandırılmasına dayanarak yapılmaktadır. Bu sınıflamaya göre; düzeltilmiş ayak açısı $90-45^{\circ}$ arasında ise 4 puan, $45-20^{\circ}$ arasında ise 3 puan, $20-0^{\circ}$ arasında ise 2 puan ve nötralden öteye $20^{\circ}$ düzeltilebiliyorsa 1 puan verilmektedir (horizontal ve sagittal planda dört ayrı komponent $4 \times 4=16$ puan) (Şekil 1 ). Statik muayene bulguları da 4 puan olmak üzere, toplam 20 puan üzerinden deformitenin değerlendirilmesi yapılmaktadır. Puanlama sonuçlarına göre, deformitenin şiddeti dört ayrı gruba ayrılır. Tablo 2'de sınıflamanın ayrıntıları gösterilmektedir.

Flynn ve arkadaşları, ${ }^{[8]}$ yaptıkları çalışmada, Pirani ve Dimeglio sınıflamalarının araştırıcılar arasındaki güvenilirliğini incelemişler ve öğrenme dönemini takiben her iki sınıflamanın da güvenilir bulunduğunu bildirmişlerdir. Wainwright ve arkadaşları ${ }^{[9]}$ ise, yayımladıkları bir çalışmada, 4 ayrı sınıflamanın (Ponseti ve Smoley, Dimeglio, Catterall, Harold ve Walker) güvenilirliklerini 


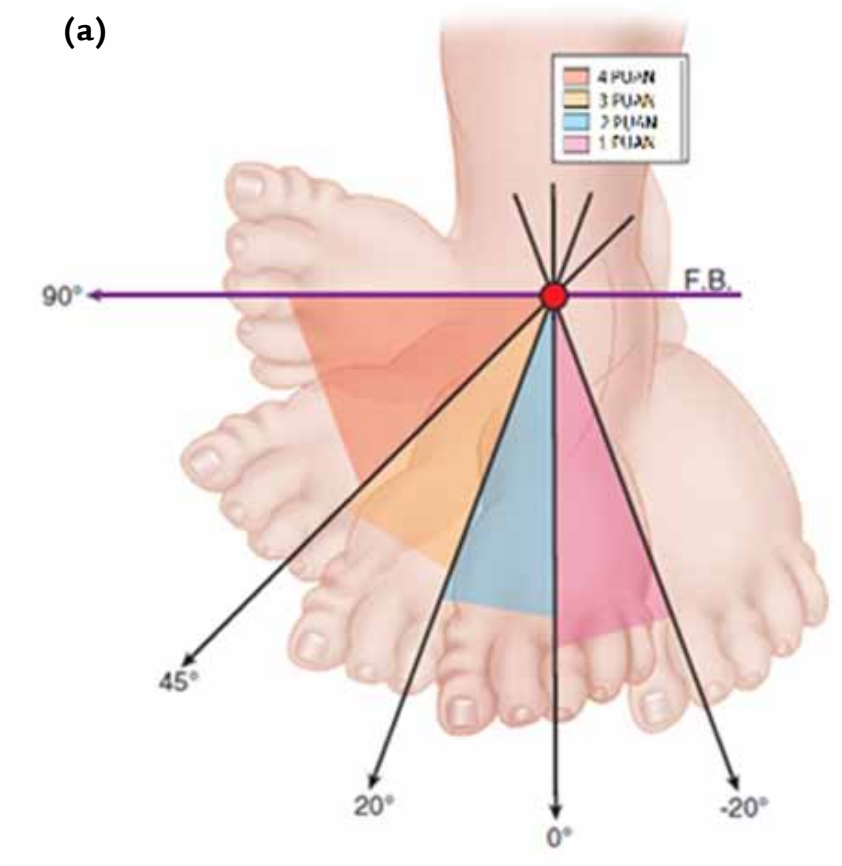

(b)
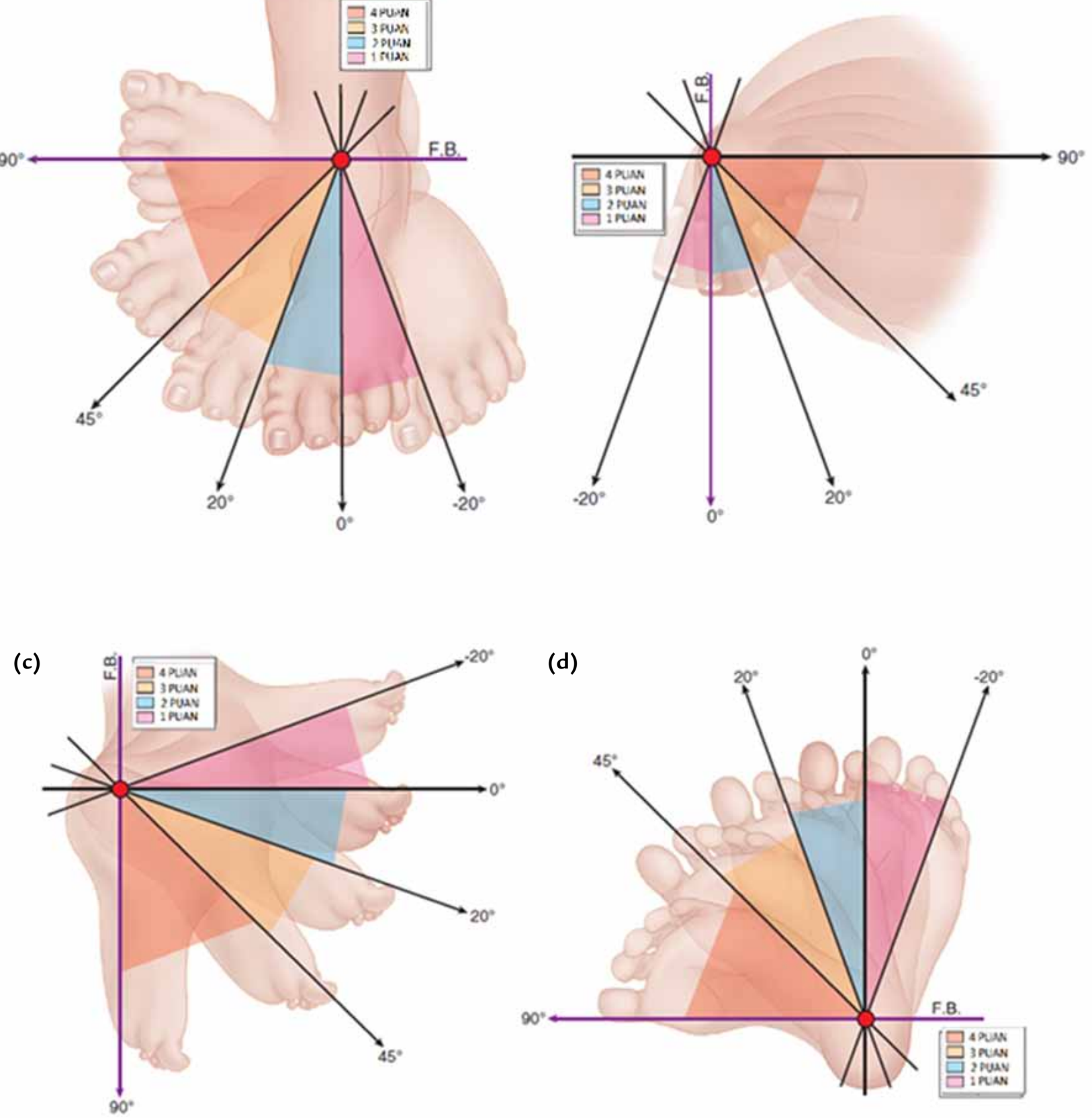

Şekil 1. PEV şiddetinin Dimeglio sınıflaması: ekinus deviyasyonu (a); varus deviyasyonu (b); derotasyon (c); adduksiyon (d). Dimeglio A, Bensahel, H, Souchet P, Mazeau P, Bonnet F. Classification of clubfoot. J Pediatr Orthop 1995;4(2):129-36.'dan türkçeleştirilmiştir.

değerlendirmişler, bu sınıflamalar içerisinde Dimeglio sınıflamasını en güvenilir bulduklarını, ancak mevcut sınıflamalardan hiçbirinin tam anlamıyla yeterli kabul edilemeyeceğini bildirmişlerdir. Dyer ve arkadaşları, ${ }^{10]}$ PEV olgularının Pirani sınıflamasına göre değerlendirildiği bir çalışmada, deformitenin şiddeti ile düzeltici alçı sayısının ilişkili olduğunu iddia ederken; Gao ve arkadaşları, ${ }^{[11]}$ çarpık ayaklı olguların prognozunun, düzeltici alçı sayısı ile ilişkilendirildiğinde, Dimeglio ve Pirani sınıflamalarının şiddeti ile korelasyon göstermediğini bildirmişlerdir. Benzer bir şekilde, Chu ve arkadaşları, ${ }^{[12]}$ deformite şiddeti ile (Dimeglio ve Pirani sınıflamalarına göre) düzeltici alçı sayısının ilişkili olmadığını, ancak deformitenin şiddetinin arttığı 
Tablo 2. PEV şiddetinin Dimeglio sınıflaması*

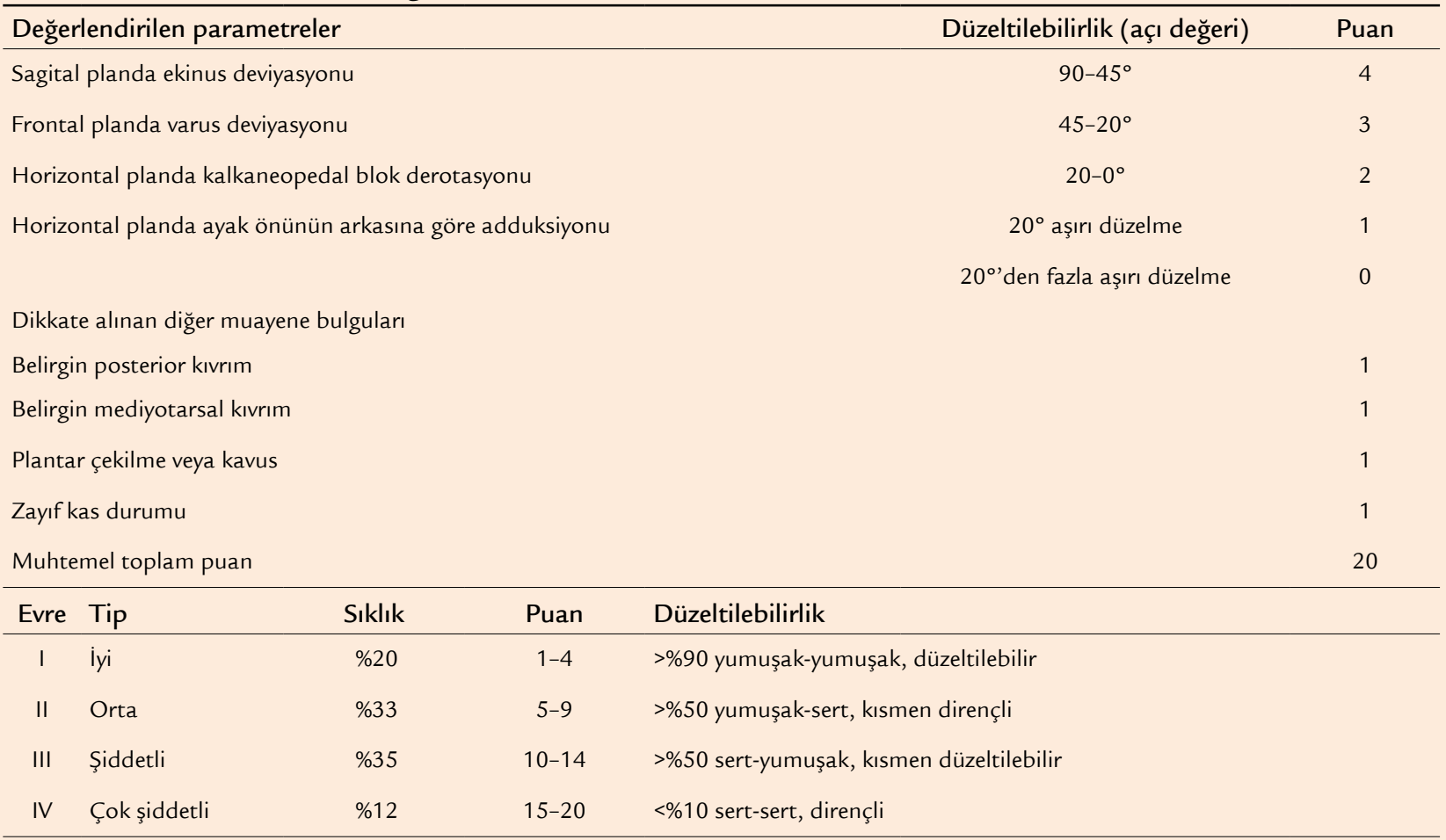

*Dimeglio A, Bensahel, H, Souchet P, Mazeau P, Bonnet F. Classification of clubfoot. J Pediatr Orthop 1995;4(2):129-36.'dan türkçeleştirilmiştir.

durumlarda, tenotomi ihtiyacının da arttığını göstermişlerdir. Scher ve arkadaşları ${ }^{[13]}$ ise, çalışmalarında Pirani skorunun 5'in üzerinde olduğunu ve Dimeglio IV olarak sınıflandırılan hastaların tedavisinde tenotomi gerektiğini bildirmişlerdir.

Görüldüğü üzere, PEV sınıflamaları olguların şiddetinin belirlenmesinde ve çalışmaların birbirleriyle karşılaştırılabilmesinde büyük katkı sağlamış olmakla birlikte, tüm araştırıcıların hemfikir olduğu, prognoz konusunda ön fikir veren, tedaviyi tüm ayrıntıları ile yönlendirebilen mükemmel bir sınıflama, hala geliştirilebilmiş değildir. Bu konuda, ortak çalışma gruplarının geliştireceği sınıflamalara ihtiyaç devam etmektedir.

\section{KAYNAKLAR}

1. Ponseti IV, Smoley EN. The classic: congenital club foot: the results of treatment. Clin Orthop Relat Res 2009;467(5):1133-45. CrossRef

2. Harrold AJ, Walker CJ. Treatment and prognosis in congenital club foot. J Bone Joint Surg Br 1983;65(1):8-11.

3. Catterall A. A method of assessment of the clubfoot deformity. Clin Orthop Relat Res 1991;(264):48-53.

4. Carroll NC. Preoperative Clinical Evaluation of Clubfoot. In: Simons GW, editor. The Clubfoot: The Present and a View of the Future. New York, NY: Springer-Verlag; 1994. p.97-8.
5. Pandey S, Pandey AK. Clinical classification of congenital clubfeet. In: Simons GW, editor. The Clubfoot: The Present and a View of the Future. New York, NY: Springer Verlag; 1994. p.91-2.

6. Dimeglio $A$, Bensahel $H$, Souchet $P$, Mazeau $P$, Bonnet $F$. Classification of clubfoot.J Pediatr Orthop 1995;4(2):129-36.

7. Pirani S, Outerbridge H, Moran M, Sawatsky BJ. A method of evaluating the virgin clubfoot with substantial inter-observer reliability. In: POSNA, Vol. 71, Miami, Florida; 1995. p.99.

8. Flynn JM, Donohoe M, Mackenzie WG. An independent assessment of two clubfoot-classification systems. J Pediatr Orthop 1998;18(3):323-7.

9. Wainwright AM, Auld T, Benson MK, Theologis TN. The classification of congenital talipes equinovarus. J Bone Joint Surg Br 2002;84(7):1020-4.

10. Dyer PJ, Davis N. The role of the Pirani scoring system in the management of clubfoot by the Ponseti method. J Bone Joint Surg Br 2006;88(8):1082-4.

11. Gao R, Tomlinson M, Walker C. Correlation of Pirani and Dimeglio scores with number of Ponseti casts required for clubfoot correction. J Pediatr Orthop 2014;34(6):639-42. CrossRef

12. Chu A, Labar AS, Sala DA, van Bosse HJ, Lehman WB. Clubfoot classification: correlation with Ponseti cast treatment. J Pediatr Orthop 2010;30(7):695-9. CrossRef

13. Scher DM, Feldman DS, van Bosse HJ, Sala DA, Lehman WB. Predicting the need for tenotomy in the Ponseti method for correction of clubfeet. J Pediatr Orthop 2004;24(4):349-52. 